\title{
FIJADOR VERTEBRAL POSTERIOR TRANSPEDICULAR OMEGA 21
}

\author{
Magda Duarte Cifuentes*
}

\section{Resumen}

El sistema OMEGA 21 es una instrumentación de apoyo pedicular, diseñado para proporcionar soporte mecánico y estabilidad a la columna dorsolumbar y lumbosacra. El OMEGA 21 posee algunos caracteres específicos de gran versatilidad, completamente originales, que le hacen aplicable a toda patología dorsolumbar y lumbosacra que requiera una estabilización instrumentada por vía posterior.

\section{Introducción}

En el año de 1958, se inicia una etapa en la cirugía del raquis, cuando se da a conocer una instrumentación que permite aplicar directamente sobre las vértebras fuerzas de gran magnitud, de actuación constante, reducción eficaz de las deformaciones axiales y a mantener esta reducción hasta que alcance la fusión ósea que la haga permanente.

Esta instrumentación utiliza como puntos de aplicación de la fuerza unos ganchos que se encajan en las laminas del arco posterior y, por imposición mecánica del sistema, el tipo de fuerza aplicada sobre el raquis sólo puede ser de comprensión o distracción. En el año de 1970 se describe por primera vez el uso sistemático del pedículo como punto de apoyo para la fijación vertebral.

La evolución de esta idea sigue tres direcciones. En la primera, surgen algunos sistemas apoyados a la vez en tomillos pediculares y en ganchos subliminares. $\mathrm{Su}$ indicación fundamental es el tratamiento de las deformidades axiales y, eventualmente, de algunas fracturas. La segunda se desarrolla en el sentido de depurar algunos inconvenientes del sistema.

La tercera dirección del desarrollo proporciona una nueva innovación conceptual importante. To-

Instrumentadora Quirúrgica, Fundación Universitaria de Ciencias de la Salud., Bogotá, D.C., Colombia

Con la colaboración de Industrias Quirúrgicas de Levante, S.L. Una compañía BIOMET MERCK y SUPLEMÉDICOS mando también punto de apoyo en los pedículos, inserta y atornilla percutáneamente en ellos unos largos vástagos, que sirven de brazos de palanca sobre los que se aplica todo tipo de fuerza necesaria para la reducci ón de las fracturas.

Más tarde se mejora, internalizando el sistema y convirtiéndolo en un fijador interno para el raquis.

\section{Características}

El sistema OMEGA 21 está fabricado en una aleación quirúrgica de titanio. Ello permite el estudio diagnóstico y los controles evolutivos de cualquier patología vertebral o intrarraquídea mediante imágenes postoperatorias con resonancia magnética sin grave distorsión. Dispone de tornillos, conectores, barras y elementos de unión transversal.

El implante ha sido sometido a un exhaustivo análisis biomecánico antes de ser utilizado en la clínica humana. Este análisis biomecánico del dispositivo OMEGA 21 demuestra en términos absolutos, que el implante cumple todos los parámetros de resistencia mecánica, en pruebas dinámicas, que la FDA norteamericana impone a los sistemas pediculares permanentes destinados al raquis dorsolumbar. Esta agencia exige una resistencia mecánica de un millón y medio de ciclos.

El OMEGA 21 ha superado los cinco millones de ciclos en las pruebas utilizadas en el laboratorio 
de la Universidad de Tulane. Resulta muy sencillo de manejar y posee algunos caracteres específicos nuevos, que disminuyen los riesgos de esta cirugía. Además. permite instrumentar vértebras osteoporóticas, se puede utilizar como un sistema de rescate en reintervenciones y elimina la necesidad de hacer presa en la cortical anterior del sacro (Figura 1).

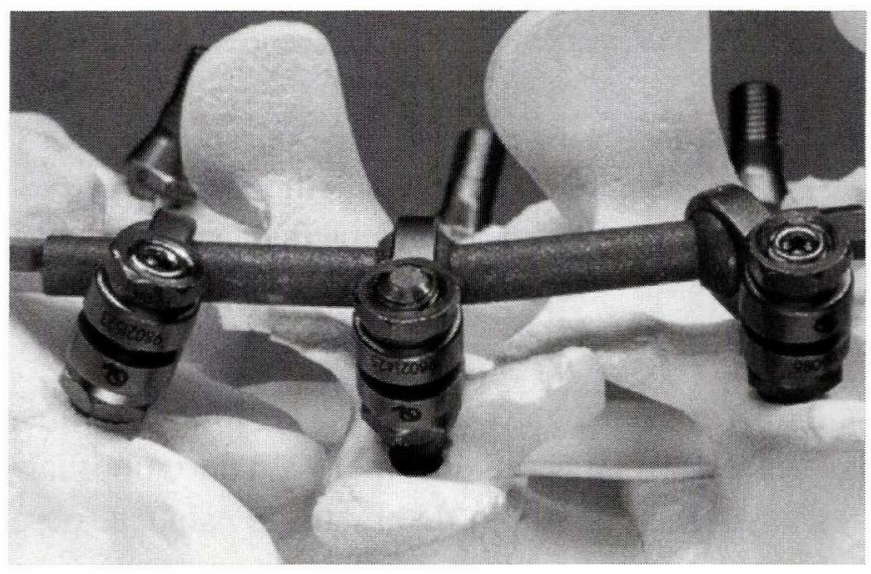

Figura 1

\section{Materiales \\ Implantes}

La posibilidad de disponer de diferentes tipos de tornillos como los son los tornillos pediculares expansivos, con su sencillo mecanismo permite que su tercio anterior aumente de diámetro una vez introducido en el cuerpo de la vértebra, ofreciendo una excelente resistencia a las fuerzas de extracción lo que resulta de suma eficacia en casos de hueso osteoporótico, reintervenciones o fijación sacral. Dispone de tornillos especiales para espondilolistesis y pediculares ambos autorroscantes y cuenta con tres tipos de conectores: el acople multidireccional posee una rótula intermedia que proporciona un ajuste del tornillo sobre la barra en todos los planos, sagital, transversal y coronal, con ello se minimiza la necesidad de contornear la barra para superar obstáculos anatómicos.

Además, encontramos los conectores simples y multidireccionales de orificios desplazados.Las características específicas de cada uno de ellos son las que dan gran versatilidad al sistema y amplían sus indicaciones.

\section{Instrumental}

CAJA A

\section{Bandeja 1}

1: Brocas y terrajas .

- Brocas: 5,5 mm, 6,5mm y 7,5 mm.

- terrajas: 7,0 mm 1x ; 8,0 mm 1x.

2: Perforador pedicular (recto y curvo).

3: Palpador pedicular (2x).

4: Porta brocas.

5: Punzón pedicular.

\section{Bandeja 2}

6: Llave antirotación hexagonal (2x).

7: Llave de $9 \mathrm{~mm}(2 \mathrm{x})$.

8: Sujeta tornillos $(2 \mathrm{x})$.

\section{Bandeja 3}

9: Estabilizador (2x).

10: Posicionador de barras (2x).

11: Herramienta para tornillos de espondilolistesis.

12: Doblador de barras francés.

13: Portabarras $(2 \mathrm{x})$.

14: Pinza conector transversal y portabarras transversal.

\section{CAJA B}

\section{Bandeja 1}

15: Llave dinamométrica $6 \mathrm{~mm}$.

16: Llave dinamométrica $9 \mathrm{~mm}$.

17: Llave canulada en T $9 \mathrm{~mm}$.

18: Llave de $6 \mathrm{~mm}$.

\section{Bandeja 2}

19: Pinza compresión.

20: Pinza distracción.

21: Atornillador Allen de 2,5 mm.

\section{Técnica quirúrgíca}

Se coloca al paciente para un abordaje posterior, para llevar a cabo la incisión según los niveles afectados, con el fin de exponer los arcos posteriores e identificar las estructuras óseas (Figuras 2 y 3).

Luego, se utiliza el intensificador de imágenes para lograr una adecuada orientación en el pedículo (Figura 4). 


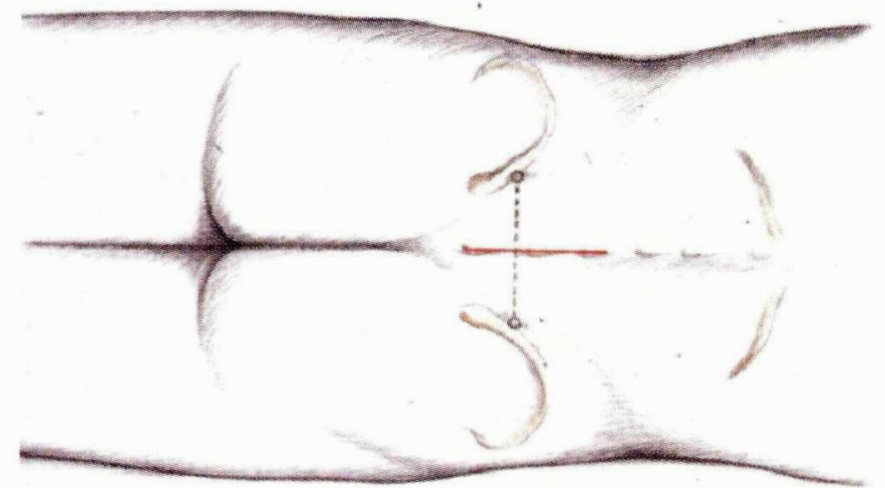

Figura 2

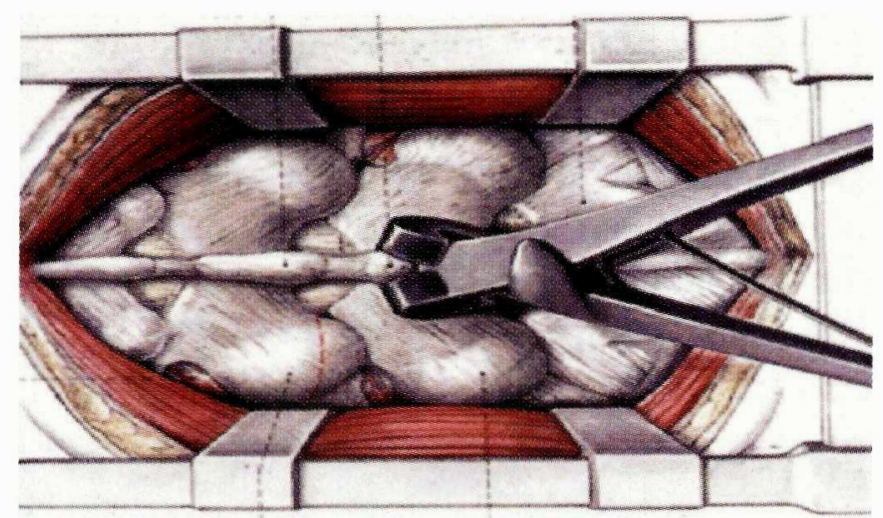

Figura 3
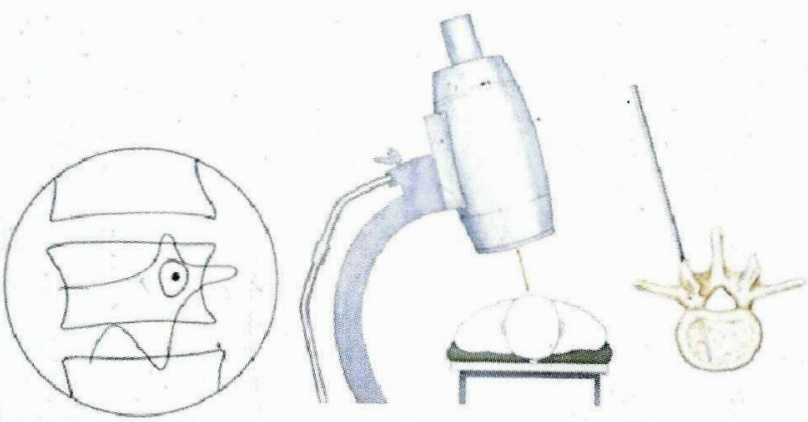

Figura 4

Otros métodos para localizar los pedículos: eliminar el anillo cortical en el punto de inicio del pedículo; cruce de las líneas entre las carillas articulares y las apófisis transversas.

El punzón pedicular (229034) es utilizado para perforar el cortex posterior en el punto de acceso al pedículo (Figura 5).

La sonda pedicular (curva 592040 ó recta 592045) es introducida y avanzada a través del hueso esponjoso, hasta alcanzar el cuerpo vertebral. En la co- lumna lumbar baja, los pedículos están en ángulo de $5-10^{\circ}$. A mayor nivel, el pedículo está más orientado verticalmente (Figura 6).

Una alternativa para la sonda pedicular son las brocas (Porta brocas 591100 y brocas $5.5 \mathrm{~mm}$, 591075). Esta broca tiene la misma punta que la sonda pedicular. La broca se avanza en el hueso mediante el giro del porta brocas.

En el caso de utilizar tornillos expansivos, primero utilizar la broca con diámetro de 6,5 ó 7,5 (591065 y 591070), seguido de la terraja de 7,0 u $8,0 \mathrm{~mm}$ (229030 y 229032). Las brocas pueden servir de ayuda para verificar mediante Rayos $\mathrm{X}$ su correcta orientación.

El palpador (591055) se utiliza para evaluar, cuando el agujero está realizado, que este último está rodeado de hueso en toda su extensión (Figura 7).

Los tornillos autoterrajantes y los expansivos pueden colocarse de 2 formas: llave de $9 \mathrm{~mm}$ (229006)

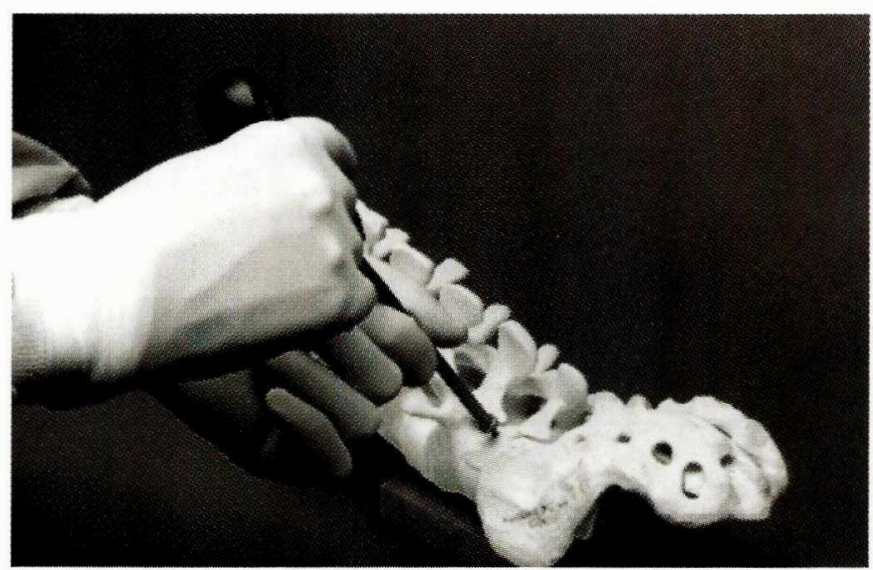

Figura 5

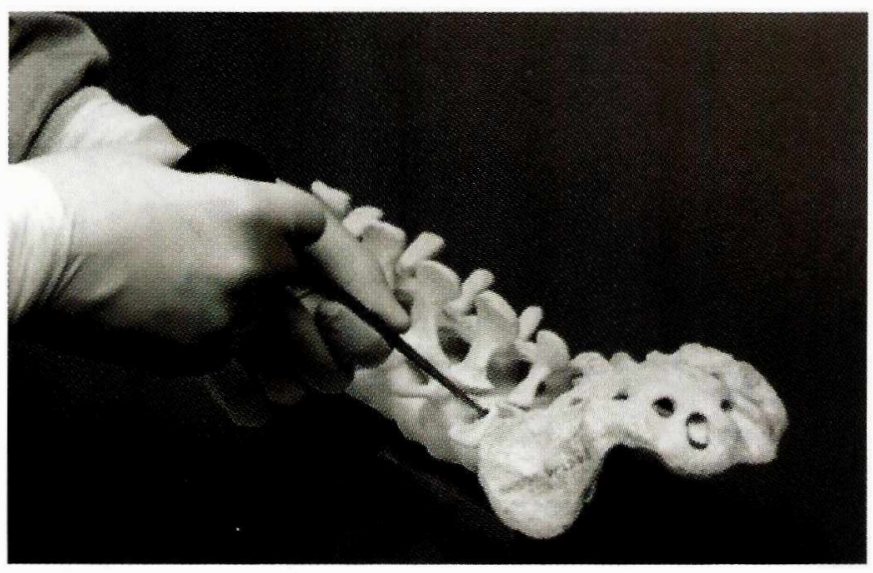

Figura 6 


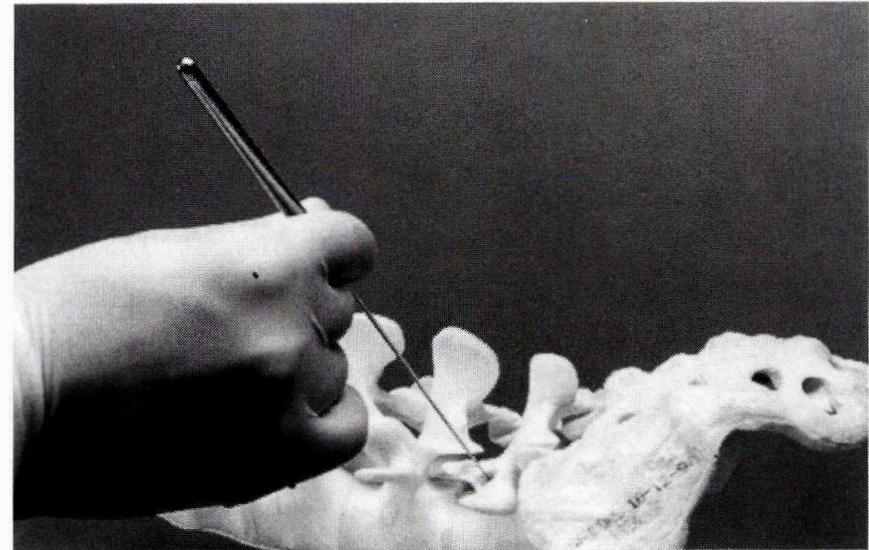

Figura 7

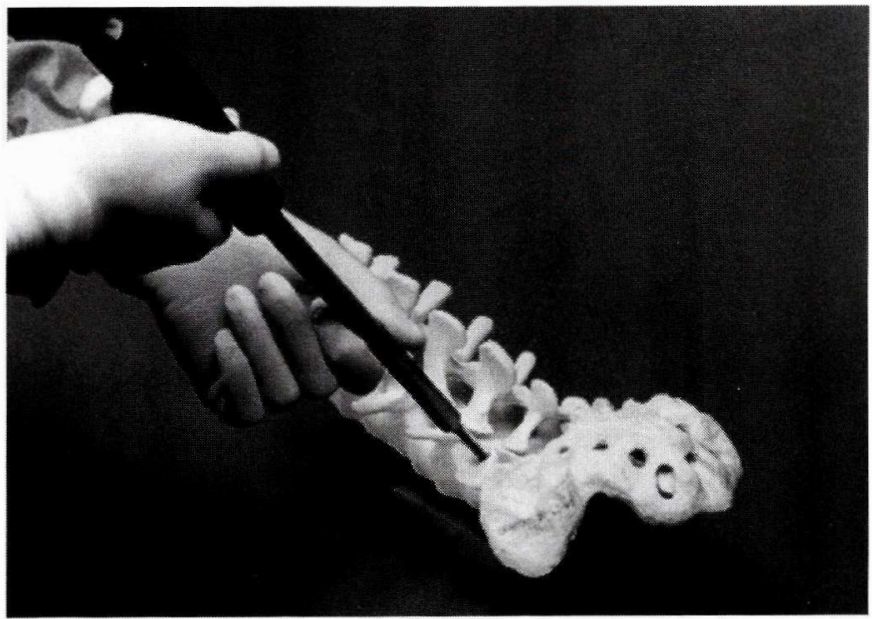

Figura 8

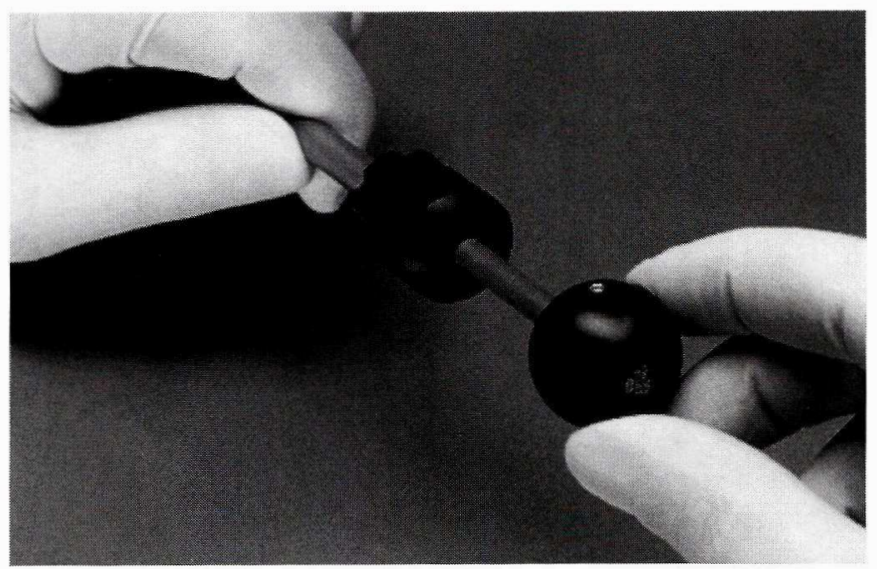

Figura 9

+ Sujetatornillos (229028) o llave canulada $9 \mathrm{~mm}$ (229022) + Sujetatornillos (229028) (Figura 8).

La herramienta para tornillos de espondilolistesis (229024) se parece al sujetatornillos (229028). Es no obstante más corto y canulado (Después de romperse la parte que le sobra, esta puede eliminarse con el atornillador Allen de 2,5 mm (229012) (Figura 9).

Antes de la introducción del tornillo expansivo, el pin debe estar colocado dentro de este, de tal manera que estén las primeras espiras sujetas y no haya abierto las aletas del tornillo expansivo. Se determina la longitud de la barra.

Los conectores (multidireccionales o agujero corrido) deben estar precargados en la barra (Figura 10).

Se coloca la barra con los conectores sobre el tornillo (con la ayuda del porta barras 229016, si fuese necesario).

Los conectores en la barra pueden alinearse a derecha o izquierda. No es necesario moldear la barra para adaptarla a un desalineamiento frontal. Se moldea la barra (Moldeador 229014), si fuese necesario para realizar más o menos lordosis (Figura 11).

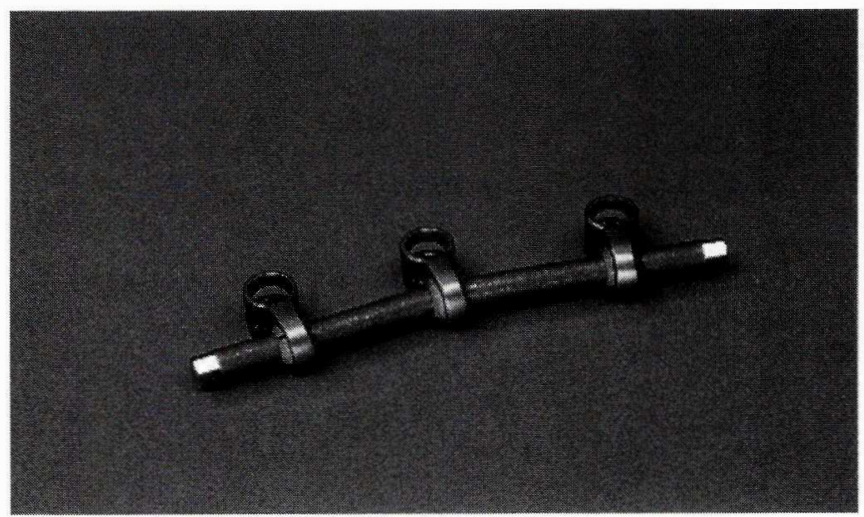

Figura 10

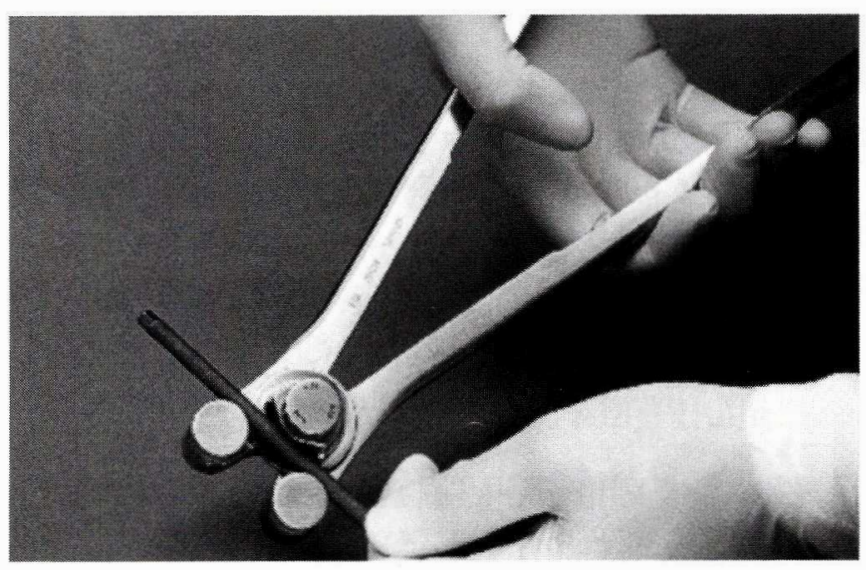

Figura 11 
Cuando la barra se moldea, se debe tener la precaución de que la lordosis esté en el plano correcto cuando se coloca. Con los posicionadores (229018), que se fijan en los extremos hexagonales de la barra, se puede rotar la barra en la dirección correcta. La llave en T de 9mm (229006) en combinación con la llave antirrotacional hexagonal (229008) se utiliza para atornillar la tuerca en cada tornillo. Se fijan mediante giro horario (Figura 12).

La compresión/distracción puede aplicarse con los respectivos instrumentales (229011 y 229010). Para realizarlo la tuerca de uno de los extremos debe estar fijada, la compresión/distracción se realiza y se fija el otro extremo para no perder este maniobra.

Los conectores transversales se pueden utilizar. Los ganchos se colocan en la barra mediante los fórceps de conector transversal (229021), mientras la barra transversal se coloca en el gancho mediante el porta barras transversal. Con la llave en $\mathrm{T}$ de $6 \mathrm{~mm}$

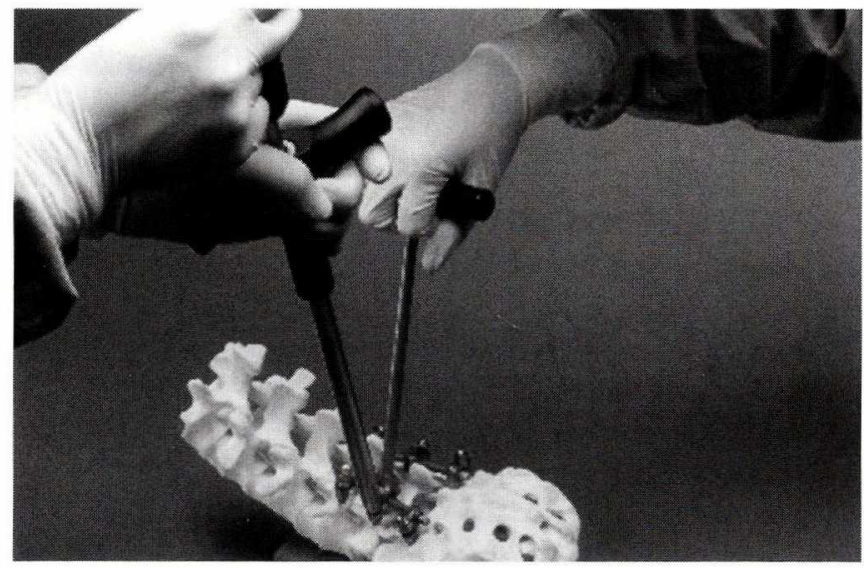

Figura 12

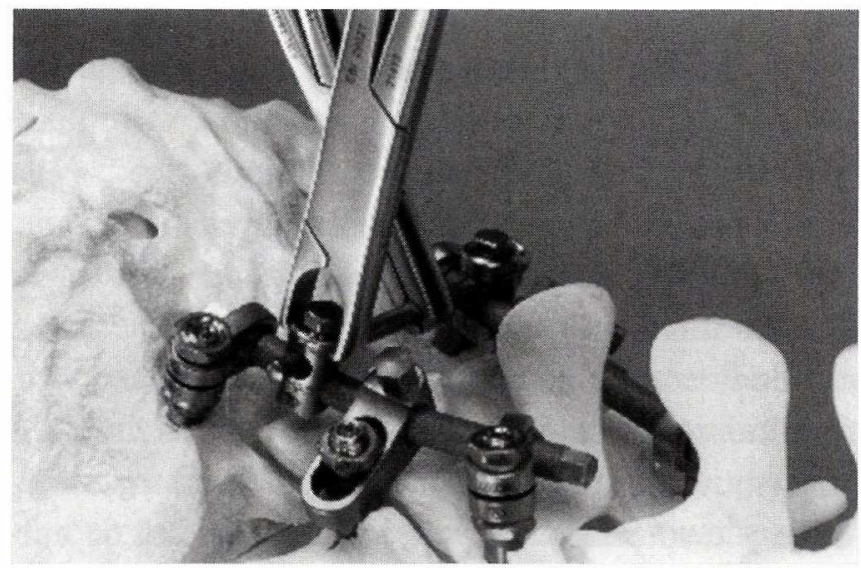

Figura 13 las tuercas de los conectores transversales se fijan (Figura 13).

$\mathrm{El}$ atornillado final de los tornillos se realiza con la llave dinamométrica de $9 \mathrm{~mm}$ en combinación con la llave antirrotacional hexagonal, que permite evitar la rotación del tornillo mientras se ajusta. No se debe forzar este instrumento.

Durante el cierre con la dinamométrica, la construcción puede estabilizarse bien con los estabilizadores o con el porta barras. Las tuercas pequeñas (en los conectores agujero corrido y enlaces transversales) se ajustan con la llave dinamométrica $6 \mathrm{~mm}$ ) (Figura 14).

Después de bloquear el sistema completamente, realizamos la expansión. El pin del tornillo expansivo, se atornilla completamente. Para evitar la rotación del tornillo utilizamos la llave en T canulada $9 \mathrm{~mm}$, a través de la cual se introduce el atornillador Allen $2,5 \mathrm{~mm}$, que va expandiendo el tornillo.

\section{Conclusiones}

Las principales conclusiones del presente trabajo, respecto a las ventajas de la utilización del Sistema OMEGA 21, se puede resumir como sigue: manejo muy sencillo y cómodo; sistema Idóneo para reintervenciones; instrumentación en vértebras osteoporóticas; ajuste del tornillo sobre la barra en todos los planos; permite el posicionamiento interno y externo de las barras; bloqueo del sistema con una sola tuerca; gran resistencia a la extracción o pull-out.

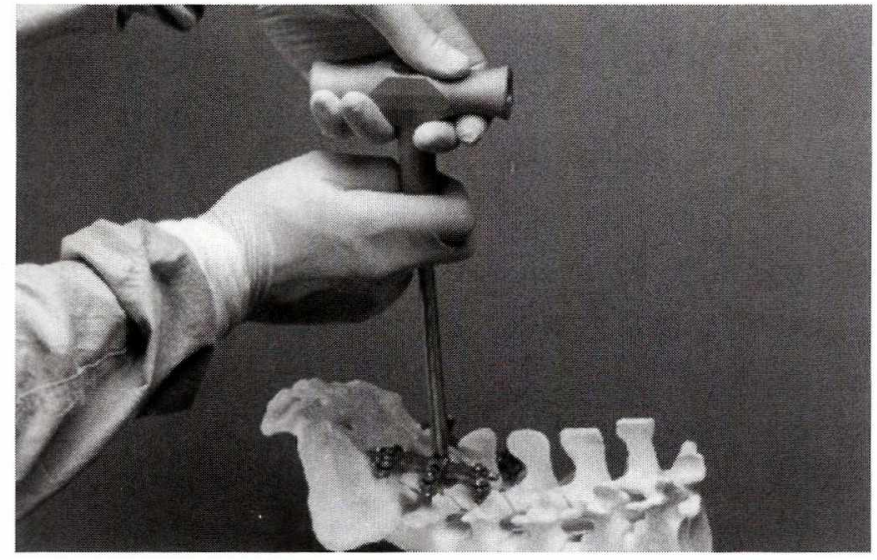

Figura 14 